\title{
Study on Eco-Friendly Concrete Blocks without Cement and Curing
}

\author{
Balamuralikrishnan. $\mathrm{R}^{1}$, Krishnamurthy. B. $\mathrm{S}^{2}$ \\ ${ }^{1}$ Asst. Professor, ${ }^{2}$ Senior Lecturer, Dept. of Built and Natural Environment, Caledonian College of \\ Engineering, Muscat, Sultanate of Oman) \\ ${ }^{1}$ Corresponding author: bmk.gaya@gmail.com
}

\begin{abstract}
Cement is the binding agent in concrete and mortar and thus becomes an important construction material. Because of its important and varied use in the rapidly growing construction industry and also its consumption trends in the world makes the production of cement very high. Manufacturing of cement is an energy intensive process and releases approximately equal amount of greenhouse gases into the atmosphere, which affects the earth's ecosystem. More efforts are being undertaken to conserve energy by means of usage of industrial wastes or by-products, such as fly ash, silica fume, ground granulated blast furnace slag, rice husk ash, etc., containing amorphous silica in its chemical composition, as mineral admixture for partial replacement of cement. Since the cement industry is one of the prime producers of carbon dioxide, creating up to $7 \%$ of worldwide man made emissions of this gas, it is necessary to find out complete replacement of cement in construction industry. Geopolymer binder is an innovative construction material and a real eco - friendly alternative to conventional cement. Geopolymer binder is a combination of alumina silicate as base material in alkaline solution. The alumina silicate is available in natural minerals as well as industrial by-products. Sodium or potassium silicate and hydroxide mixture forms the alkaline solution. The use of geopolymer binder in concrete can be a great alternative to cement in the construction industry, which will result in saving of energy, environmental protection and conversation of resources. An attempt is made to develop the geopolymer concrete in Oman using low calcium fly ash obtained from India. This investigation consists of three studies. In the first study, development of mix proportions of various grades of geopolymer concrete such as C25, C30 and C40. The mix proportion of geopolymer of various grades obtained based on the mix proportions given in ACI code with hundred percent replacement of cement by fly ash. The compressive strength of geopolymer concrete is achieved by adjusting the concentration of sodium hydroxide in the alkaline solution. The strength of geopolymer concrete is achieved in 24 hours after casting of specimens by heat curing. The results obtained are encouraging and similar to the corresponding strength of cement concrete. In the second study, the developed geopolymer concrete of C25 grade is used to cast the solid block of size $200 \times 200 \times 400 \mathrm{~mm}$. In the third study, a beam i.e. prism of size 100x100x500mm with two point loading study was done. The strength properties of the block and the beam are comparable with the strength values of conventional concrete of corresponding grade. Hence, the geopolymer technology can be effectively used in the construction industry in terms of saving energy consumption and resources and ultimately to save the ecosystem of earth.
\end{abstract}

Keywords: Cement concrete; Geopolymer concrete; Fly ash; Sodium; hydroxide; Sodium silicate; Heat curing; Compressive strength

\section{Introduction}

\subsection{Global Pollution due to Cement Industry}

Cement production increases at about $3 \%$ per year. This rate is set to increase as developing nations rapidly become richer, and spend proportionately more cement intensive infrastructures (McCaffrey, 2002). The production of one ton of Portland cement contributes approximately one ton of $\mathrm{CO} 2$ to the atmosphere. Globally, the world's Portland cement production contributes about 2.5 billion tons of $\mathrm{CO} 2$ or about $7 \%$ of the global loading of carbon dioxide into the atmosphere. In order to address the environmental effect associated with Portland cement, there is a need to use other binders to make concrete. One of the efforts to produce more environmental friendly concrete is to replace the amount of Portland cement in concrete with by-product materials such as fly ash. An important achievement in this regard is the development of high volume fly ash concrete that utilizes up to 60 percent of fly ash, and yet possesses excellent mechanical properties with enhanced durability performance (Malhotra, 2009).

\subsection{Cement Concrete}

Concrete is the most widely used construction material in the world. It is used in many different structures such as dam, pavement, building frame or bridge. Also, it is the most widely used material in the world, far exceeding other materials. Its worldwide production exceeds that of steel by a factor of 10 in tonnage 
and by more than a factor of 30 in volume. The present consumption of concrete is over 10 billion tons a year, that is, each person on earth consumes more than 1.7 ton of concrete per year. It is more than 10 times of the consumption by weight of steel. The partial replacement of cement by a pozzolanic mineral admixture reduces the production cost of concrete. The reduction of excess $\mathrm{Ca}\left(\mathrm{OH}_{2}\right)$ due to pozzolanic reaction improves durability of concrete by making cement paste more dense and impervious. The addition of admixtures acts as scavengers for penetration of chloride ions, which prevents corrosions of steel in the concrete. The reduction of compressive strength of concrete, flexural strength of concrete at early ages and increasing carbonation of concrete are found on some of the drawbacks in the partial replacement of cement by fly ash in concrete.

\subsection{Geopolymer Concrete \\ 1.3.1 Geopolymer}

Alkaline solution and fly ash is a basic material to form polymerization process that involves a substantially fast chemical reaction under alkaline condition on Silicon and Aluminium to produce binder is called "geopolymer". The geopolymer concrete (GPC) is a mixture of geopolymer, coarse and fine aggregates. The sodium silicate solution and sodium hydroxide solids, i.e. commercially available sodium silicate solution with $\mathrm{SiO}_{2}$ to $\mathrm{Na}_{2} \mathrm{O}$ ratio by mass of approximately 2, i.e., $\mathrm{Na}_{2} \mathrm{O}-14.7 \%, \mathrm{SiO}_{2}-29.40 \%$, and water $-55.90 \%$ by mass, and sodium hydroxide solids $(\mathrm{NaOH})$ with $97-98 \%$ purity, are recommended. Laboratory experience suggests that the ratio of sodium silicate solution to sodium hydroxide solution by mass may be taken approximately as 2.5 . The alkaline solution to fly ash ratios are kept as 0.45 (Hardjitio and Rangan 2008).

\subsubsection{Polymerization of Geopolymer}

Davidovits (2005) proposed that an alkaline liquid could be used to react with the silicon ( $\mathrm{Si}$ ) and the aluminum ( $\mathrm{Al}$ ) in a source material of geological origin or in by-product materials such as fly ash and rice husk ash to produce binders. Because the chemical reaction that takes place in this case is a polymerization process, he coined the term 'Geopolymer' to represent these binders. Geopolymers are members of the family of inorganic polymers. The chemical composition of the geopolymer material is similar to natural zeolitic materials, but the microstructure is amorphous (Davidovits, 1988). The polymerization process involves a substantially fast chemical reaction under alkaline condition on $\mathrm{Si}-\mathrm{Al}$ minerals that result in a three-dimensional polymeric chain and ring structure consisting of $\mathrm{Si}-\mathrm{O}-\mathrm{Al}-\mathrm{O}$ bonds.

The last term of equation 2 shows that water is released during the formation of geopolymer. This water, expelled from the geopolymer matrix during the curing and further drying periods, leaves behind nanopores in the matrix, which provide benefits to the performance of geopolymers. The water in a geopolymer mixture, therefore, plays no role in the chemical reaction that takes place; it merely provides the workability to the mixture during handling. This is in contrast to the chemical reaction of water in a portland cement concrete mixture during the hydration process (Rangan, 2008, Lloyd and Rangan, 2009, Rangan et al 2011)

\subsubsection{Sodium hydroxide $(\mathrm{NaOH})$}

Generally the sodium hydroxides are available in solid state by means of pellets and flakes. The cost of the sodium hydroxide is mainly varied according to the purity of the substance. Since our geopolymer concrete is homogenous material and its main process is to activate the sodium silicate, it is recommended to use the lowest cost i.e. up to $94 \%$ to $96 \%$ purity.

\subsubsection{Sodium silicate $\left(\mathrm{Na}_{2} \mathrm{SiO}_{3}\right)$}

Sodium silicate is also known as water glass or liquid glass, available in liquid (gel) form. As per the manufacturer, silicates are supplied to the detergent company and textile industry as bonding agent, same sodium silicate is used for the making of geopolymer concrete.

\subsubsection{Activator solution}

Generally alkaline liquids are prepared by mixing of the sodium hydroxide solution and sodium silicate at the room temperature. When the solutions are mixed together they start to react i.e. (polymerization takes place) and liberate large amount of heat so it is recommended to leave it for about 24 hours thus the alkaline liquid is get ready as binding agent. Sodium hydroxide pellets are taken and dissolved in the water at the rate of different molar concentrations. It is strongly recommended that the sodium hydroxide solution must be prepared 24 hours prior to the use and also if it exceeds 36 hours it converts into semi solid state.

\subsection{Geopolymer (Eco - friendly) Concrete (GPC)}

\section{Experimental Investigation}

There are two main constituents of geopolymers, namely the source materials and the alkaline liquids. The source materials for geopolymers based on alumina-silicate should be rich in silicon ( $\mathrm{Si}$ ) and aluminium (Al). 
These could be natural minerals such as kaolinite, clays, etc. Alternatively, by-product materials such as fly ash, silica fume, slag, rice-husk ash, red mud, etc could be used as source materials. The choice of the source materials for making geopolymers depends on factors such as availability, cost, type of application, and specific demand of the end users. The alkaline liquids are from soluble alkali metals that are usually Sodium or Potassium based. The most common alkaline liquid used in geopolymerisation is a combination of sodium hydroxide $(\mathrm{NaOH})$ or potassium hydroxide $(\mathrm{KOH})$ and sodium silicate or potassium silicate.

\subsection{Constituents of Geopolymer Concrete (GPC)}

Geopolymer concrete can be manufactured by using the low-calcium (ASTM Class F) fly ash obtained from coal-burning power stations. Most of the fly ash available globally is low-calcium fly ash formed as a byproduct of burning anthracite or bituminous coal. Although coal burning power plants are considered to be environmentally unfriendly, the extent of power generated by these plants is on the increase due to the huge reserves of good quality coal available worldwide and the low cost of power produced from these sources. Lowcalcium fly ash has been successfully used to manufacture geopolymer concrete when the silicon and aluminum oxides constituted about $80 \%$ by mass, with the Si-to- $\mathrm{Al}$ ratio of about 2 . The content of the iron oxide usually ranged from 10 to $20 \%$ by mass, whereas the calcium oxide content was less than $5 \%$ by mass. The carbon content of the fly ash, as indicated by the loss on ignition by mass, was as low as less than $2 \%$. Coarse and fine aggregates used by the concrete industry are suitable to manufacture geopolymer concrete. A combination of sodium silicate solution and sodium hydroxide $(\mathrm{NaOH})$ solution can be used as the alkaline liquid. It is recommended that the alkaline liquid is prepared by mixing both the solutions together at least 24 hours prior to use. The sodium silicate solution is commercially available in different grades. The sodium silicate solution A53 with $\mathrm{SiO}_{2}$-to- $\mathrm{Na}_{2} \mathrm{O}$ ratio by mass of approximately 2, i.e., $\mathrm{SiO}_{2}=29.4 \%, \mathrm{Na}_{2} \mathrm{O}=14.7 \%$, and water $=55.9 \%$ by mass, is generally used.

The sodium hydroxide with $97-98 \%$ purity, in flake or pellet form, is commercially available. The solids must be dissolved in water to make a solution with the required concentration. The concentration of sodium hydroxide solution can vary in the range between 8 Molar and 16 Molar; however, 8 Molar solution is adequate for most applications. The mass of $\mathrm{NaOH}$ solids in a solution varies depending on the concentration of the solution. For instance, $\mathrm{NaOH}$ solution with a concentration of 8 Molar consists of $8 \times 40=320$ grams of $\mathrm{NaOH}$ solids per litre of the solution, where 40 is the molecular weight of $\mathrm{NaOH}$.

\subsection{Mixture Proportions of Geopolymer Concrete (GPC)}

The primary difference between geopolymer concrete and Portland cement concrete is the binder. The silicon and aluminum oxides in the low-calcium fly ash reacts with the alkaline liquid to form the geopolymer paste that binds the loose coarse aggregates, fine aggregates, and other un-reacted materials together to form the geopolymer concrete. As in the case of Portland cement concrete, the coarse and fine aggregates occupy about 75 to $80 \%$ of the mass of geopolymer concrete. This component of geopolymer concrete mixtures can be designed using the tools currently available for Portland cement concrete. The compressive strength and the workability of geopolymer concrete are influenced by the proportions and properties of the constituent materials that make the geopolymer paste.

As can be seen from the above, the interaction of various parameters on the compressive strength and the workability of geopolymer concrete is complex. In order to assist the design of low-calcium fly ash-based geopolymer concrete mixtures, a single parameter called 'water-to-geopolymer solids ratio' by mass was devised. The mass of geopolymer solids is the sum of the mass of fly ash, the mass of sodium hydroxide solids used to make the sodium hydroxide solution, and the mass of solids in the sodium silicate solution (i.e. the mass of $\mathrm{Na}_{2} \mathrm{O}$ and $\mathrm{SiO}_{2}$ ).

\subsection{Aggregates}

Coarse and fine aggregates used by the concrete industry are suitable to manufacture geopolymer concrete. The aggregate grading curves currently used in concrete practice are applicable in the case of geopolymer concrete. The properties of aggregates used are listed below:

- $\quad$ Specific gravity of fine aggregate $(\mathrm{G})=2.65$

- Specific gravity of coarse aggregate $(\mathrm{G})=2.70$

- $\quad$ Fineness modulus $=2.80$ (medium sand)

- Fineness modulus $=2.30$ (coarse aggregate of size ranging from 12.5 to $5 \mathrm{~mm}$ )

\subsection{Alkaline liquid}

It is recommended that the alkaline liquid is prepared by mixing sodium silicate and sodium hydroxide solutions together at least 24 hours prior to use for thorough mixing and reaction. The sodium silicate solution is 
commercially available in different grades. The sodium silicate solution with sodium hydroxide ratio by mass of 2.5 is used (Fig.1 to 3 ).

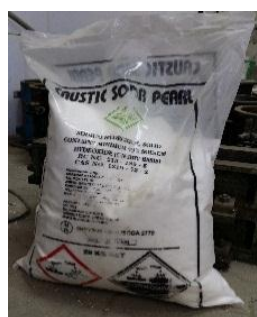

Fig. 1 Sodium Hydroxide $(\mathrm{NaOH})$

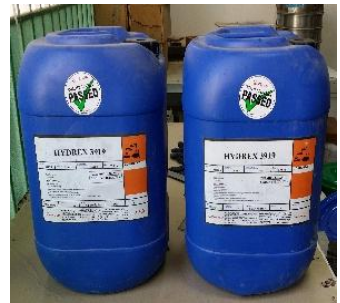

Fig. 2 Sodium Silicate $\left(\mathrm{Na}_{2} \mathrm{SiO}_{3}\right)$

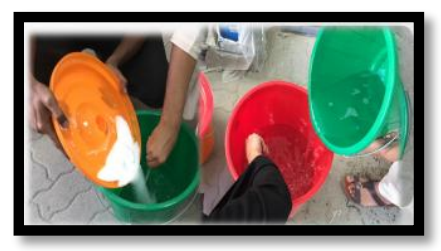

Fig.3 Mixing of Alkaline Solution (8M)

The sodium hydroxide with $97-98 \%$ purity in pellet form is commercially available. The solids dissolved in water to make a solution with the required concentration. The concentrations of sodium hydroxide solution are kept as 8 Mole, 10 Mole and 12 Mole. The mass of $\mathrm{NaOH}$ solids in a solution varies depending on the concentration of the solution. The constituents of geopolymer concrete for different grade and mole is presented in Table 1.

Table 1 Constituents of geopolymer concrete $\left(\operatorname{Per} 1 \mathrm{~m}^{3}\right)$

\begin{tabular}{|c|c|c|c|c|c|c|c|}
\hline $\begin{array}{c}\text { Sl. } \\
\text { No. }\end{array}$ & Mix Ratio & $\begin{array}{c}\text { Flyash } \\
\text { kg. }\end{array}$ & $\begin{array}{c}\text { Fine Agg. } \\
\text { kg. }\end{array}$ & $\begin{array}{c}\text { Coarse Agg. } \\
\text { kg. }\end{array}$ & Mole & $\begin{array}{c}\text { Sodium Silicate / } \\
\text { Sodium Hydroxide }\end{array}$ & $\begin{array}{c}\text { (Sodium Silicate + Sodium } \\
\text { Hydroxide) / Flyash }\end{array}$ \\
\hline 1. & C25 & 343 & 852 & 982 & $8 \mathrm{M}$ & 2.5 & 0.45 \\
\hline 2. & C30 & 394 & 799.7 & 982 & $10 \mathrm{M}$ & 2.5 & 0.45 \\
\hline 3. & C40 & 500 & 691.6 & 982 & $12 \mathrm{M}$ & 2.5 & 0.45 \\
\hline
\end{tabular}

\subsection{Preparation of specimens}

The concrete batch is mixed on a water tight, non-absorbent steel platform with a shovel, trowel and similar suitable implement, using the following procedure.

i. The fly ash and FA are mixed dry until the mixture is thoroughly blended and is uniform in colour.

ii. The coarse aggregate is added and mixed with the fly ash and fine aggregate until the coarse aggregate is uniformly distributed throughout the batch. The ingredients of geopolymer concrete (GPC) and mixing procedure are shown in Fig.4 to 7.

iii. The chemical solution is added and the entire batch is mixed until the concrete appears to be homogenous and has the desired consistency. If repeated mixing is necessary, because of the addition water in increments while adjusting the consistency, the batch is to be discarded and fresh batch is made.

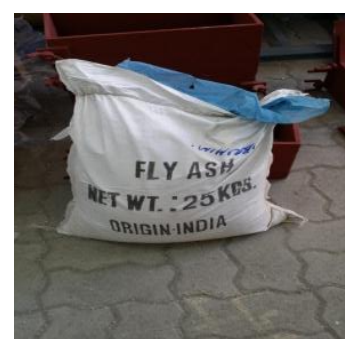

Fig.4 Flyash

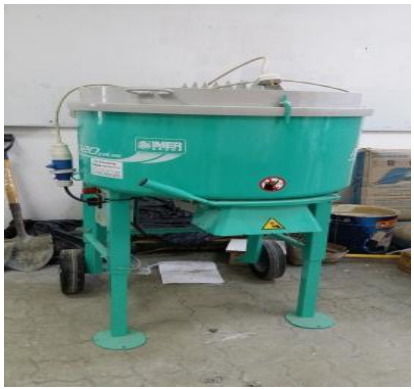

Fig.6 GPC mixing in the pan mixer

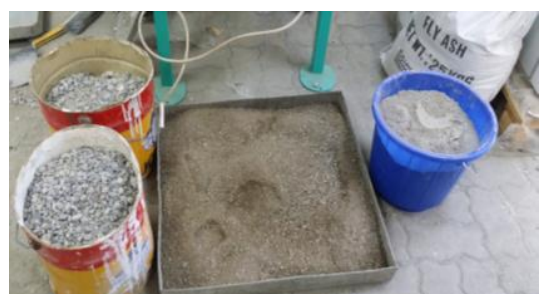

Fig.5 Fine aggregate, coarse aggregate and flyash

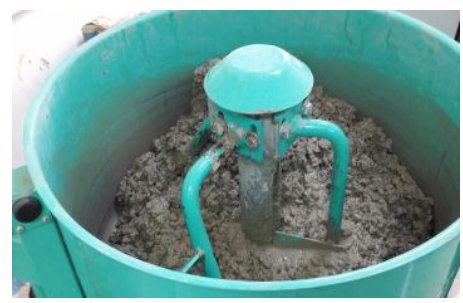

Fig.7 Closer view of mixing 


\subsection{Study 1: Development of geopolymer concrete with different grades and mole}

Totally 18 Nos of concrete cubes (CC) and 18 Nos of GPC cubes of size $150 \times 150 \times 150 \mathrm{~mm}$ for 8 Mole, 10 Mole and 12 Mole for $\mathrm{C} 25, \mathrm{C} 30$ and C40 concrete mix respectively were tested to find their compressive strength and optimum mole for 7 days, 14 days and 28 days strength. The mix was designed as per ACI code. In this study three different mix ratio and three different mole were taken for investigation.

\subsection{Study 2: Development of Precast Elements (Solid Block)}

Totally 6 Nos of concrete cubes blocks (CC) and 6 Nos of GPC blocks of size $400 \times 200 \times 200 \mathrm{~mm}$ for 8 Mole concrete mix was tested to find their compressive strength for 7 days, 14 days and 28 days strength.

\subsection{Study 3: Flexural Strength of GPC beam (prism)}

Totally 6 Nos of concrete prisms(CC) and 18Nos of GPC prism of size $500 \times 100 \times 100$ mm for 8 Molar, 10 molar and 12 Molar were tested to find their flexural strength for 7 days, 14 days and 28 days strength and compare with conventional concrete prism.

\subsection{Mixing, casting and curing}

The fresh fly ash classified as low calcium (ASTM Class F) dry ash collected from Thermal Power Station, India was used. The aggregates were prepared in saturated surface dry condition. The liquid part of the mixture, i.e. the sodium silicate solution, and the sodium hydroxide solution mixed twenty four hours earlier for thorough mixing and reaction. The solids constituents of the fly ash based geopolymer concrete, i.e. the aggregates and the fly ash were dry mixed by a pan mixer for about three minutes. The wet mixing of liquid and dry mixture of aggregates usually continued for another four minutes. The casting process of cubes, blocks and prisms for both geopolymer concrete (GPC) and conventional concrete (CC) are shown in Figs.8 to 11. The wet mixing usually is in cohesive condition. The workability of the fresh concrete was measured by means of the conventional slump test. The slump measured was $50 \mathrm{~mm}$. The prepared GPC specimens like one set of cubes, prism and solid blocks with $8 \mathrm{M}$, second set of cubes with $10 \mathrm{M}$ and finally third set of cubes with $12 \mathrm{M}$ were kept in moulds. After casting the specimens were covered using vacuum bagging film. Curing at $65^{\circ} \mathrm{C}$ was done in hot curing chamber for 17 hours. Curing process in the hot- curing chamber is shown Figs. 12 to 15 . After 17 hours from hot curing chambers the GPC specimens are ready for testing.

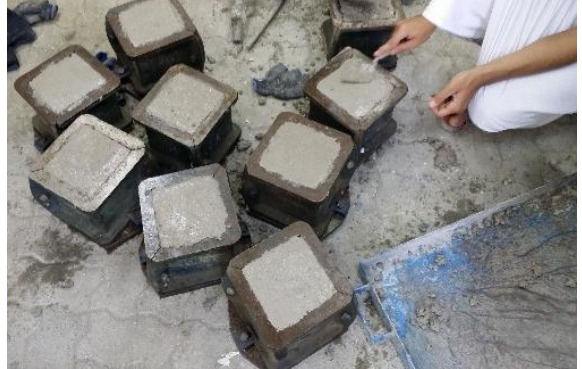

Fig.8 Casting of GPC Cubes

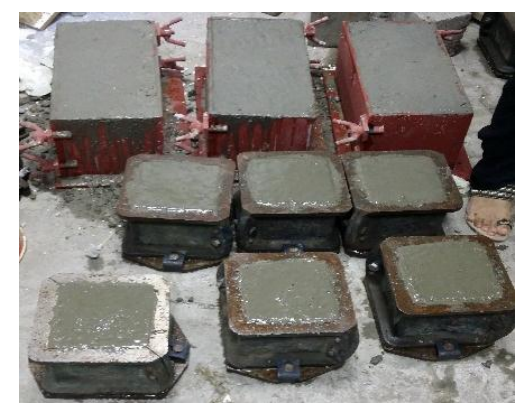

Fig.10 Casting of Solid Blocks

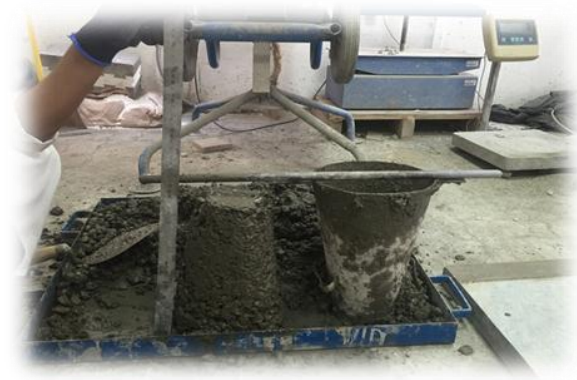

Fig.9 Slump Test for GPC

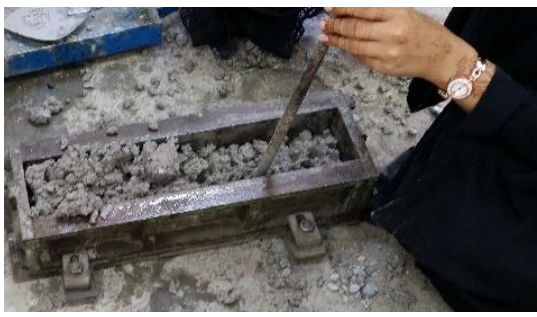

Fig.11Casting of Prism 


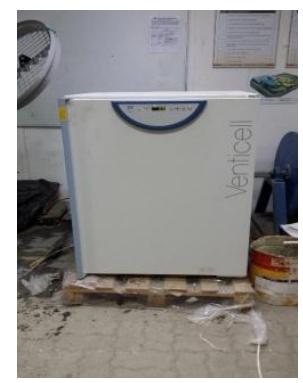

Fig.12 Heat Chamber

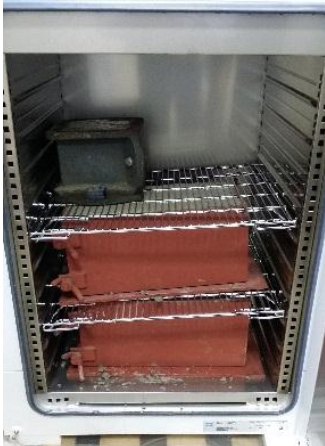

Fig.14 Blocks in Heat Chamber

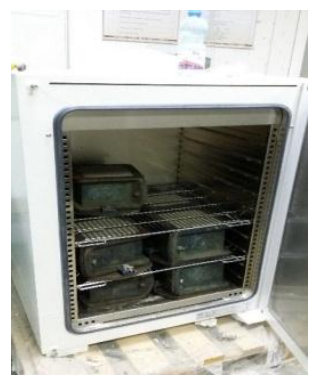

Fig.13 Cubes in Heat Chamber

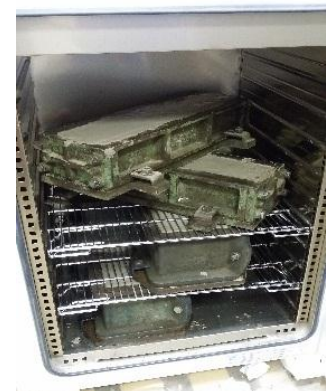

Fig.15 Prisms in Heat Chamber

The geopolymer concrete (GPC) specimensfor different mix ratio and different mole after casting are kept in room temperature for 7, 14 and 28 days tested, keeping smooth surface of the cube in contact with loading. The compressive strength machine of $1000 \mathrm{kN}$ capacity is used to apply the axial force of compression. The load is gradually applied until failure occurred. The testing of cubes, blocks are shown in Figs.16 and 17. The similar testing procedure was adopted in conventional concrete specimens (CC) also. The test result for different mole and grades of geopolymer concrete (GPC) and cement concrete (CC) is presented in Table 2.

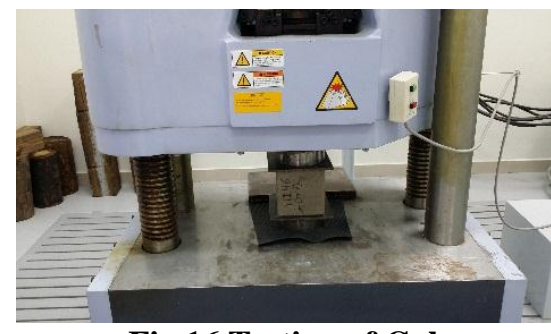

Fig.16 Testing of Cubes

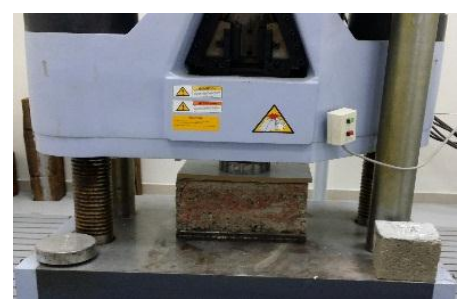

Fig.17 Testing of Blocks

The conventional cement concrete for C25, C30 and C40 grade test results for 7,14 and 28 days are presented in Table 3. The C25 blocks with 8 mole were tested at an age of 7 days, 14 days and 28 days and the results are presented in Table 4 . The corresponding conventional concrete (CC) blocks test details are presented in Table 5.

Table 2 Cube compressive strength of GPC for different grade of concrete and mole

\begin{tabular}{|c|c|c|c|c|c|c|c|c|c|}
\hline \multirow[t]{2}{*}{ Sl. No. } & \multirow[t]{2}{*}{$\begin{array}{c}\text { Mix } \\
\text { Ratio }\end{array}$} & \multirow[t]{2}{*}{$\begin{array}{l}\text { Mole of } \mathrm{NaOH} \\
\text { Solution }\end{array}$} & \multirow[t]{2}{*}{$\begin{array}{c}\text { Slump } \\
\text { mm }\end{array}$} & \multirow[t]{2}{*}{$\begin{array}{l}\text { Curing } \\
\text { Method }\end{array}$} & \multirow{2}{*}{$\begin{array}{c}\text { Curing } \\
\text { Time in } \\
\text { Hours }\end{array}$} & \multirow[t]{2}{*}{$\begin{array}{l}\text { Curing } \\
\text { Temp. }\end{array}$} & \multicolumn{3}{|c|}{$\begin{array}{c}\text { Average Comp. Strength } \\
\text { MPa }\end{array}$} \\
\hline & & & & & & & 7 day & 14 day & 28 day \\
\hline \multirow{3}{*}{1.} & \multirow{3}{*}{$\mathrm{C25}$} & $8 \mathrm{M}$ & 50 & Heat & 24 & $65^{\circ} \mathrm{C}$ & 15.00 & 16.00 & 18.90 \\
\hline & & $10 \mathrm{M}$ & 50 & Heat & 24 & $65^{\circ} \mathrm{C}$ & 12.00 & 14.50 & 14.50 \\
\hline & & $12 \mathrm{M}$ & 50 & Heat & 24 & $65^{\circ} \mathrm{C}$ & 10.00 & 13.00 & 13.00 \\
\hline \multirow{3}{*}{2.} & \multirow{3}{*}{$\mathrm{C30}$} & $8 \mathrm{M}$ & 50 & Heat & 24 & $65^{\circ} \mathrm{C}$ & 23.00 & 24.00 & 26.50 \\
\hline & & $10 \mathrm{M}$ & 50 & Heat & 24 & $65^{\circ} \mathrm{C}$ & 13.00 & 15.00 & 15.50 \\
\hline & & $12 \mathrm{M}$ & 50 & Heat & 24 & $65^{\circ} \mathrm{C}$ & 11.00 & 13.00 & 14.00 \\
\hline \multirow{3}{*}{3.} & \multirow{3}{*}{$\mathrm{C40}$} & $8 \mathrm{M}$ & 50 & Heat & 24 & $65^{\circ} \mathrm{C}$ & 27.00 & 29.00 & 31.00 \\
\hline & & $10 \mathrm{M}$ & 50 & Heat & 24 & $65^{\circ} \mathrm{C}$ & 16.00 & 18.00 & 21.00 \\
\hline & & $12 \mathrm{M}$ & 50 & Heat & 24 & $65^{\circ} \mathrm{C}$ & 14.00 & 15.00 & 16.00 \\
\hline
\end{tabular}


Table 3 Compressive strength of $\mathrm{C25}, \mathrm{C30}$ and $\mathrm{C40}$ grade conventional concrete $(\mathrm{CC})$

\begin{tabular}{|c|c|c|c|c|}
\hline \multirow{2}{*}{ Sl. No. } & \multirow{2}{*}{\begin{tabular}{c} 
Rix \\
\cline { 3 - 5 }
\end{tabular}} & \multicolumn{3}{|c|}{$\begin{array}{c}\text { Average Comp. Strength } \\
\text { Ratio }\end{array}$} \\
\cline { 3 - 5 } & & $\mathbf{7 ~ d a y}$ & $\mathbf{1 4}$ day & $\mathbf{2 8}$ day \\
\hline 1 & C25 & 19.00 & 23.00 & 27.00 \\
\hline 2 & C 30 & 27.75 & 28.15 & 33.50 \\
\hline 3 & C40 & 27.31 & 37.04 & 43.50 \\
\hline
\end{tabular}

\begin{tabular}{|c|c|c|c|c|c|}
\hline Sl. No. & \multirow{2}{*}{ Mix Ratio } & NaOH concentration & \multicolumn{3}{|c|}{ Solid block compressive strength } \\
\cline { 4 - 6 } & & & $\mathbf{7}$ day & $\mathbf{1 4}$ day & $\mathbf{2 8}$ day \\
\hline 1. & $\mathrm{C} 25$ & $8 \mathrm{M}$ & 7.00 & 8.00 & 9.20 \\
\hline
\end{tabular}

Table 4 Compressive strength of C25 grade GPC solid block

Table 5 Compressive strength of $\mathrm{C} 25$ grade conventional cement concrete CC solid block

\begin{tabular}{|c|c|c|c|c|}
\hline \multirow{2}{*}{ Sl. No. } & \multirow{2}{*}{ Mix Ratio } & \multicolumn{3}{|c|}{ Solid block compressive strength } \\
\cline { 3 - 5 } & & $\mathbf{7}$ days & $\mathbf{1 4}$ days & $\mathbf{2 8}$ days \\
\hline 1. & C25 & 9.00 & 11.0 & 12.75 \\
\hline
\end{tabular}

\subsection{Flexural Strength Test for Prisms (GPC and CC)}

The flexural strength of hardened concrete was measured by performing the prism flexural test. These specimens were tested by universal testing machine $1000 \mathrm{kN}$ (UTM) after 7, 14 and 28 days curing. The specimen was placed on two supporting pins a set distance apart and a two point loading pin is lowered from above at a constant rate until sample failure (Fig.18).

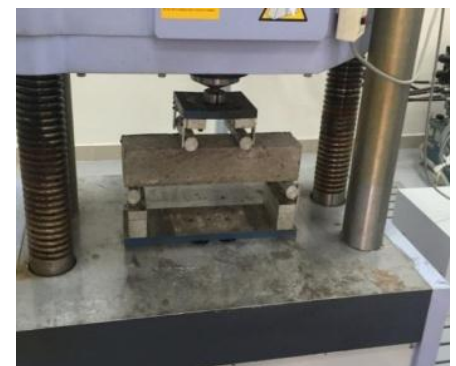

Fig.18 Flexural Strength of Prism

The results of geopolymer concrete prisms (GPC) $\mathrm{C} 40$ grade with $8 \mathrm{M}, 10 \mathrm{M}$ and $12 \mathrm{M}$ and conventional cement concrete prisms are shown in Table 6 and 7.

Table 6 Flexural strength of C40 grade GPC concrete with 8M, 10M and 12M

\begin{tabular}{|c|c|c|c|c|c|}
\hline \multirow[t]{2}{*}{ Sl. No. } & \multirow[t]{2}{*}{ Mix Ratio } & \multirow[t]{2}{*}{$\mathrm{NaOH}$ concentration } & \multicolumn{3}{|c|}{$\begin{array}{c}\text { Flexural strength }\left(\mathrm{N} / \mathrm{mm}^{2}\right) \\
\mathrm{Pl} / \mathrm{bd}^{2}\end{array}$} \\
\hline & & & 7 day & 14 day & 28 day \\
\hline 1 & \multirow[t]{3}{*}{$\mathrm{C} 40$} & $8 \mathrm{M}$ & 4.50 & 5.00 & 5.39 \\
\hline 2 & & $10 \mathrm{M}$ & 4.25 & 4.50 & 4.75 \\
\hline 3 & & $12 \mathrm{M}$ & 1.20 & 1.64 & 1.75 \\
\hline
\end{tabular}

Table 7 Flexural strength of $\mathrm{C40}$ grade conventional concrete

\begin{tabular}{|c|c|c|c|c|}
\hline Sl. No. & \multirow{2}{*}{\begin{tabular}{c} 
Mix \\
\cline { 3 - 5 }
\end{tabular}} & Ratio & \multicolumn{3}{|c|}{$\begin{array}{c}\text { Flexural strength }\left(\mathbf{N} / \mathbf{m m}^{2}\right) \\
\text { PI/bd }^{\mathbf{2}}\end{array}$} \\
\cline { 3 - 5 } & & $\mathbf{7 ~ d a y s}$ & $\mathbf{1 4}$ days & $\mathbf{2 8}$ days \\
\hline 1. & C40 & 5.25 & 6.00 & 7.50 \\
\hline
\end{tabular}

\section{Results and Discussions}

\subsection{Study 1: Compression Test on Cubes}

\subsubsection{Different grade and different $\mathrm{NaOH}$ Concentration of Geopolymer Concrete}

The compressive strength of C 25, C30 and C40 grade GPC cubes (150x150x150mm) made with 8 M, $10 \mathrm{M}$ and12 $\mathrm{M}$ concentration of $\mathrm{NaOH}$ heat cured at $60^{\circ} \mathrm{C}$ for 24 hours and kept in room temperature for 7,14 and 28 days. The compressive strength of GPC C25, C30 and C40 grade with different NaOH concentration for 7, 14 and 28 days are shown in Fig. 19. Similarly comparison of GPC with 8M for C25, C30, C40 and CC for C25, C30 and C40 at 28 days compressive strength is shown in Fig.20.The compressive strength of geopolymer concrete decreases as the concentration of sodium hydroxide solution increases. The mole concentration of $8 \mathrm{M}$ 
of $\mathrm{NaOH}$ for $\mathrm{C} 25$ grade GPC cubes show a compressive strength of $18.90 \mathrm{MPa}$ at 28 days which is lesser than the expected target mean strength of $27.00 \mathrm{MPa}$. It is clear that $8 \mathrm{M}$ functioning well compared to $10 \mathrm{M}$ and $12 \mathrm{M}$.

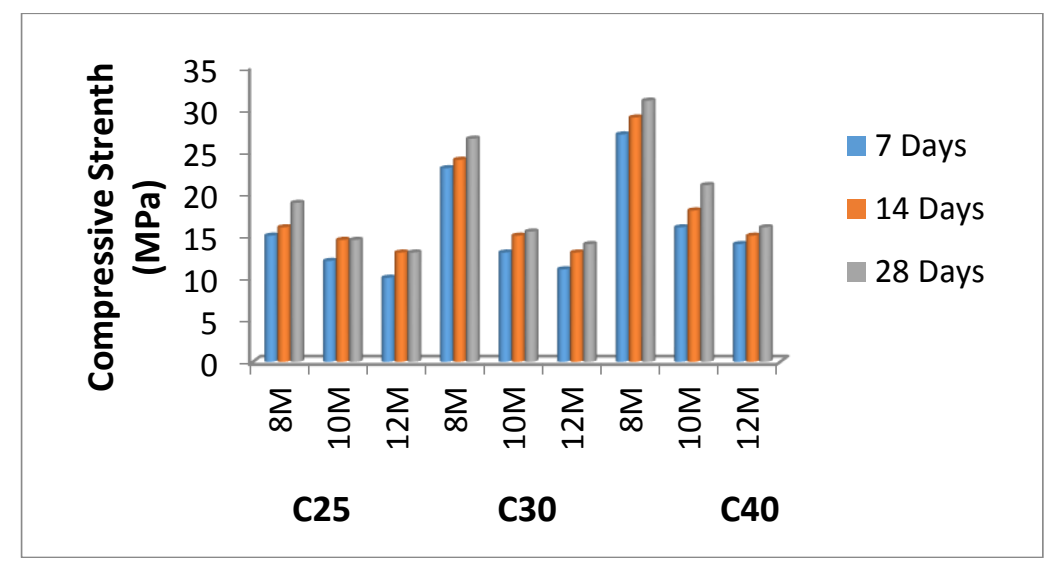

Fig. 19 Compressive Strength of Different grade of GPC with Different NaOH Concentrations

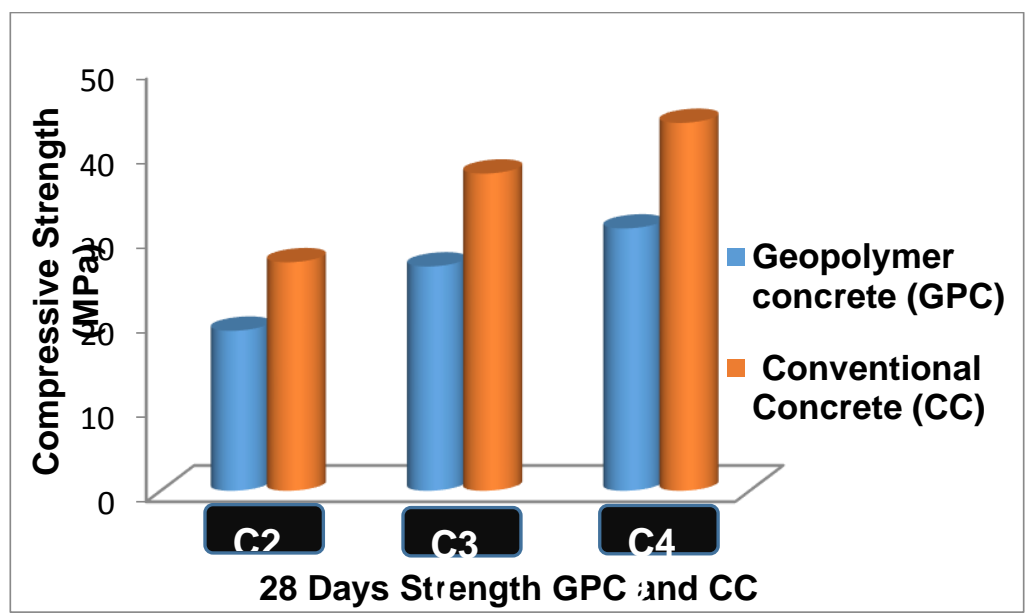

Fig.20 Compressive Strength of Different grade of GPC with $8 \mathrm{M}$ and CC at 28 days strength

Again the compressive strength of 8 mole concentration of $\mathrm{NaOH}$ for $\mathrm{C} 30$ grade GPC cubes for 28 days is $33.00 \mathrm{MPa}$ which is lesser than the required strength of $37.50 \mathrm{MPa}$, similarly C40 grade GPC with $8 \mathrm{M}$ reached $31 \mathrm{MPa}$ instead of $43.50 \mathrm{MPa}$. All the three grades with $8 \mathrm{M}$ reached 71 percent target mean strength of conventional concrete (CC) and the optimum concentration of sodium hydroxide solution in the alkaline activator is found as $8 \mathrm{M}$. The remaining $10 \mathrm{M}$ and $12 \mathrm{M}$ was reached nearly about 52 percent and 31 percent respectively.

\subsection{Study2: Compresive Strength of Solid Blocks}

The compressive strength of $\mathrm{C} 25$ grade solid block with 8 Mole, 10 Mole and 12 mole grades of CC and GPC at 7, 14 and 28 days are compared and shown in Figure 21. The compressive strength of C25 grade with $8 \mathrm{M}$ is increases with respect to age from 7 days to 28 days nearly 31 percent. For solid block study, $8 \mathrm{M}$ was taken directly based on study1. It is clear that $8 \mathrm{M}$ was achieved 72 percent of strength with respect to conventional concrete solid blocks at 28 days. 


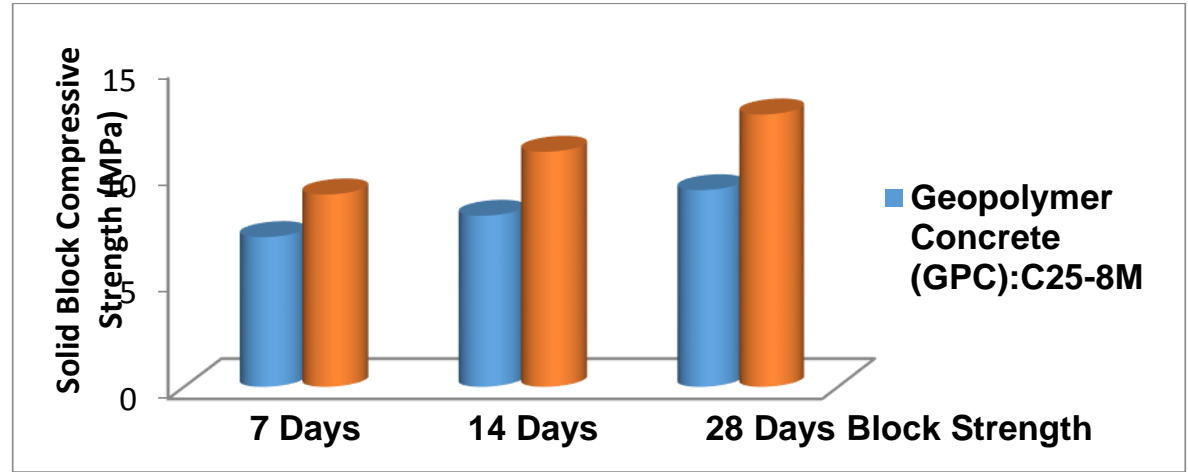

Fig.21 Compressive Strength of GPC and CC Block for 7,14 and 28 days

\subsection{Study3: Flexure Test on Prisms}

The control concrete and GPC prisms of size $100 \times 100 \times 500 \mathrm{~mm}$ are cast and tested for flexure. The flexural strength of CC and GPC and prisms of C40 grade with different mole are shown in Fig.4.4. The flexural strength decreases when increasing the mole. Flexural strength also achieved nealy 72 percent of corresponding cement concrete prism.

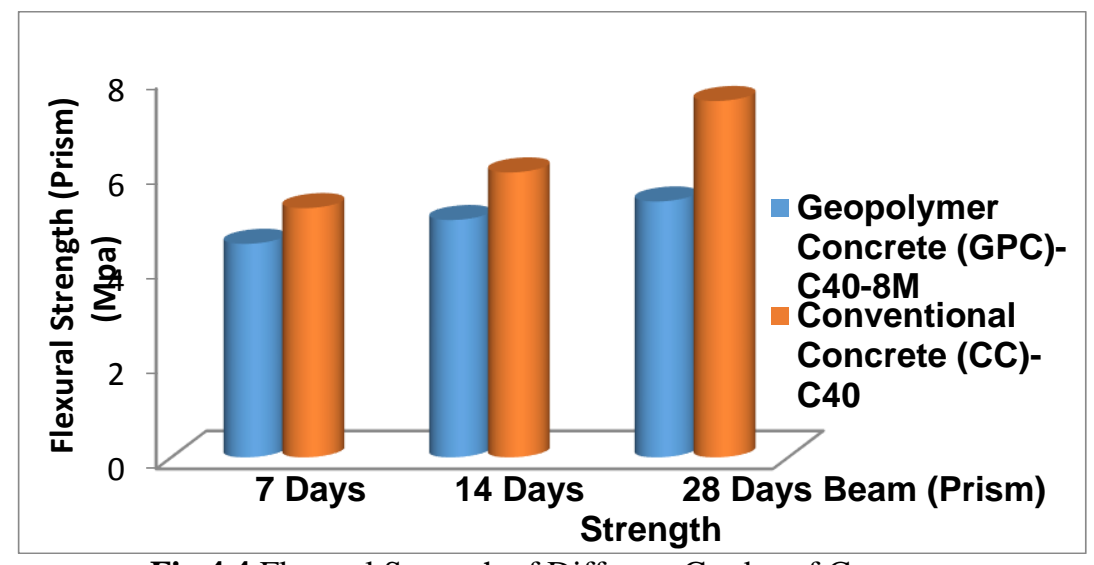

Fig.4.4 Flexural Strength of Different Grades of Concrete

\section{Conclusion}

Based on the results obtained from experiments, the salient features and the strength parameters of geopolymer concrete are observed and summarized as follows:

Study: 1 Development of GPC

1) Cement concrete mix design is carried out based on ACI committee 211.1-91 method. Control cement concrete specimens of different grades are cast, cured for 7 days, 14 days and 28 days and tested. The average compressive strength of C25, C30 and C40 grades cement concrete at 28 days is obtained as 27 , 33.50 and $43.50 \mathrm{~N} / \mathrm{mm}^{2}$ respectively.

2) Geopolymer concrete of various grades is developed using the same mix proportion obtained in control concrete with $100 \%$ replacement of cement by fly ash. The geopolymer concrete elements were heat cured at $65^{\circ} \mathrm{C}$ for 24 hours and kept in room temperature. The required strength of respective grades is obtained by adjusting the concentration of $\mathrm{NaOH}$ used in geopolymer alkaline solutions.

3) The average compressive strength of geopolymer concrete of different grades is obtained as 18.90, 26.50, and $31.00 \mathrm{~N} / \mathrm{mm}^{2}$ and compared respectively with the average compressive strength of cement concrete grades $\mathrm{C} 25, \mathrm{C} 30$ and $\mathrm{C} 40$ at 28 days.

4) The compressive strength of geopolymer concrete was found to be decreasing with the increase in the concentration of sodium hydroxide in geopolymer alkaline solution. The mole concentration of $8 \mathrm{M}$ of $\mathrm{NaOH}$ in $\mathrm{C} 25$ grade GPC cubes showed a compressive strength of 70 percent of expected target mean strength at 28 days. The compressive strength of $10 \mathrm{M}$ and $12 \mathrm{M}$ concentration of $\mathrm{NaOH}$, GPC cubes are nearly 53 percent and 48 percent of expected target mean strength at 28days. Among the three mole for C25 grade GPC, the optimum concentration of sodium hydroxide solution in the alkaline activator is found as $8 \mathrm{M}$ and the corresponding cost also is less compared to that for $10 \mathrm{M}$ and $12 \mathrm{M}$. 
5) Similarly the mole concentration of $8 \mathrm{M}$ of $\mathrm{NaOH}$ in $\mathrm{C} 30$ and $\mathrm{C} 40$ grade GPC cubes showed a compressive strength nearly 79 and 71 percent of expected target mean strength at 28 days. The compressive strength of $10 \mathrm{M}$ and $12 \mathrm{M}$ concentration of $\mathrm{NaOH}$ in $\mathrm{C} 30$ grade GPC cubes are nearly 56 and 54 percent of the expected target mean strength at 28 days. Again the compressive strength of $10 \mathrm{M}$ and $12 \mathrm{M}$ concentration of $\mathrm{NaOH}$ in $\mathrm{C} 40$ grade GPC cubes are nearly 57 and 55 percent of the expected target mean strength at 28 days. For all the three mole of C30 and C40 grade GPC, the optimum concentration of sodium hydroxide solution in the alkaline activator is found to be $8 \mathrm{M}$ when compared to $10 \mathrm{M}$ and $12 \mathrm{M}$.

6) The duration for geopolymer concrete curing temperature is $65^{\circ} \mathrm{C}$ for 24 hours in the heat curing chamber. Test was conducted on $7^{\text {th }}, 14^{\text {th }}$ and $28^{\text {th }}$ day in room temperature and the average compressive strengths of fly ash based geopolymer concrete are obtained.

7) The rate of gaining in compressive strength with age in geopolymer concrete showed a significant achievement when compared to cement concrete.

\section{Study: 2 Compressive Strength of Precast Solid blocks}

8) Similarly the mole concentration of $8 \mathrm{M}$ of $\mathrm{NaOH}$ in 25 grade GPC solid blocks for study 2 showed a compressive strength of 72 percent of the expected target mean strength of CC solid blocks at 28 days. In study 2 also $8 \mathrm{M}$ functioning was found to be the best when compared to $10 \mathrm{M}$ and $12 \mathrm{M}$.

\section{Study: 3 Flexure Behaviour on Beams (Prisms)}

9) Finally for the prism study the mole concentration of $8 \mathrm{M}$ of $\mathrm{NaOH}$ in $\mathrm{C} 40$ grade GPC prism showed a flexural strength was achieved nearly 72 percent of the expected target mean strength of CC solid blocks at 28 days. In this study also $8 \mathrm{M}$ concentration gave better strength as compared to $10 \mathrm{M}$ and $12 \mathrm{M}$ concentrations.

\section{References}

[1] Davidovits, J., Soft mineralogy and geopolymers: In Proceeding of Geopolymer 88 International Conference, The University Technologies, Compiegne, France, 2005.

[2] Hardjito, D., and Rangan, B.V., (2008). Development and properties of low calcium fly ash based geopolymer concrete, Research report GC1, Curtin University of Technology, Perth, Australia, 2008.

[3] Lloyd, N., and Rangan, B.V., Geopolymer Concrete - sustainable cementless concrete, Proceedings of Tenth ACI International conference on recent advances in concrete tehnology and sustainability issues, Seville, 2009, 33-53.

[4] Malhotra, V.M., High-performance, high-volume fly ash concrete, Concrete International, 24 (7), $2009,30-34$.

[5] McCaffrey, R., Climate change and the cement industry, Global Cement and Lime Magazine (Environmental Special Issue), 2002, 15- 19.

[6] Rangan, B.V., Fly ash based geopolymer concrete, Research report GC4, Curtin University of Technology, Perth, Australia, 2008.

[7] Rangan, B.V., Low-calcium fly ash-based geopolymer concrete, Chapter 26 in Concrete Construction Engineering Handbook, Editor-in Chief: E.G. Nawy, Second Edition, CRC Press, New York, 2011. 